\title{
Sleep Apnoea and Early Antecedents of Adult Disease
}

\author{
David Gozal, MD, MBA
}

Department of Pediatrics, Section of Sleep Medicine, Pritzker School of Medicine, Biological Sciences Division, The University of Chicago, Chicago, Illinois, USA

\section{ABSTRACT}

Obstructive sleep apnoea (OSA) is a highly prevalent disorder across the life spectrum including early childhood and pregnancy. Occurrence of sleep perturbations and intermittent hypoxia that constitute major hallmarks of OSA during these favourable developmental plasticity windows may facilitate emergence of incremental risks for a variety of ageing-related disorders via a multitude of epigenetic mechanisms. In addition, OSA during late adolescence and adulthood is not immune to epigenetic changes, the latter potentially playing a role in the reversibility of OSA-associated morbidities upon implementation of therapy. Furthermore, unique epigenetic signatures may provide powerful biomarkers for precision-based medicine approaches in the framework of OSA. Taken together, the conceptual umbrellas assigning major roles to epigenetics in the context of OSA-associated phenotypic expression and longitudinal disease risk trajectories is not a farfetched idea any longer. Early adoption of these biologically relevant principles and their implementation to the upcoming future clinical trials appears inevitable if progress is to occur. (BRN Rev. 2018;4(3):185-99) Corresponding author: David Gozal, dgozal@uchicago.edu

Key words: Epigenetics. Intermittent hypoxia. Microbiome. Sleep apnoea. Sleep fragmentation.

\section{Correspondence to:}

David Gozal, MD, MBA

Department of Pediatrics, Section of Sleep Medicine

Pritzker School of Medicine

The University of Chicago

KCBD, Room 4100, 900 E. 57th Street, Mailbox 4, Chicago, IL 60637

E-mail:dgozal@uchicago.edu

Received in original form: 20-03-2018

Accepted in final form: 06-04-2018

DOI: 10.23866/BRNRev:2017-0030 


\section{INTRODUCTION}

A large and ever-expanding body of evidence indicates that sleep disordered breathing (SDB) is a substantial and prevalent health problem in both the adult and paediatric populations. Indeed, a conservative estimate would suggest that around 5\% of children and up to $15-35 \%$ of adults in the general population suffer from the most common form of SDB. Obstructive sleep apnoea (OSA) is characterised by recurrent episodes of upper airway obstruction or partial obstruction during sleep that result in intermittent hypoxia (IH) and hypercapnia, sleep disruption, and increased intrathoracic pressure swings due to respiratory effort aimed at opening the collapsed airway. The ever-expanding interest and awareness to OSA has been predicated on the epidemiological and experimental evidence linking OSA with a large repertoire of end-organ morbidities which ultimately result in increased all-cause mortality ${ }^{1,2}$.

In this context, a substantial body of evidence has suggested that OSA is independently associated with neurocognitive, cardiovascular and metabolic morbidities ${ }^{3-5}$, and even with increased cancer prevalence and adverse outcomes ${ }^{6-10}$. However, in a recent review of the evidence focused on the potential value of screening for OSA, ambivalence was expressed as to whether treatment of OSA will reverse its associated morbidities and was found to only significantly improve excessive daytime sleepiness and quality of life $^{11}$. Furthermore, although hotly debated and contested, a large multicentre study, the Sleep Apnea Cardiovascular Endpoints (SAVE) trial, found no evidence to support the use of continuous positive airway pressure (CPAP) therapy in the secondary prevention of cardiovascular morbidity and mortality in patients with OSA ${ }^{12,13}$.

These overall findings have suggested that the presence of long-standing disease may adversely affect the reversibility of its consequences, and preliminary experimental evidence in murine models appears to support such assumption and point to the possibility that the presence of some or all of the characteristic perturbations that constitute OSA may foster selective changes in the epigenome, some of which may become irreversible $e^{14,15}$.

Here, I will briefly discuss the current understanding of epigenetics in the context of OSA and review the evidence on how this disease can impose a variety of epigenetic modifications which conditional on their occurrence at various stages of life can then promote risk of long-term morbidities or attenuate the reversibility of such morbidities. I should however emphasise that individuals suffering from OSA at any age are exposed to their unique environmental conditions and evolve in their very personal lifestyle, both of which can also impose major modifications to the cogwheel of OSA-induced morbidity, in addition to the contributions attributable to genetic background and epigenetic modifications discussed below (Fig. 1).

\section{EPIGENETICS AND DEVELOPMENTAL ORIGINS OF HEALTH AND DISEASE}

Since the original proposal by Barker on the early life origins of human disease ${ }^{16}$, and the conceptual framework leading to the current eponym of DOHAD (Developmental Origins of 


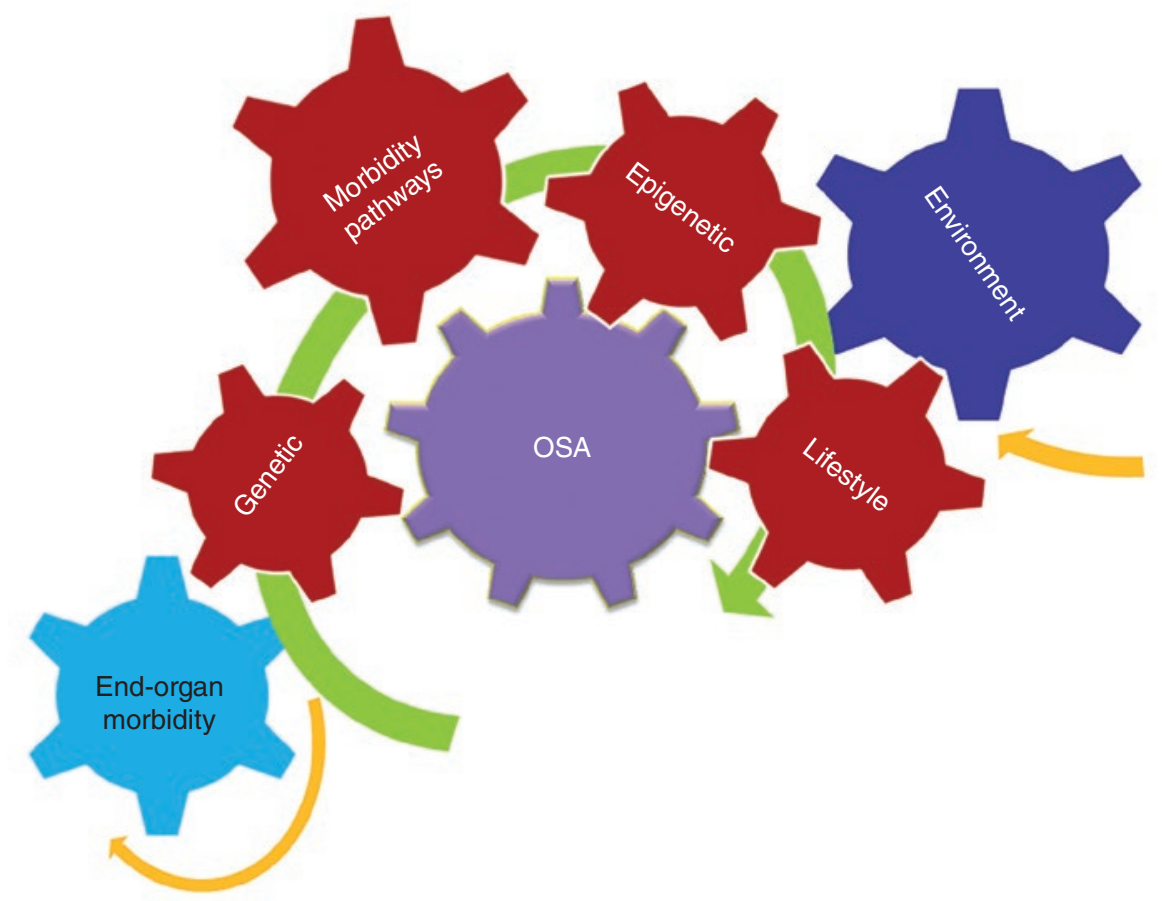

Figure 1. Schematic illustrating how environment, lifestyle, individual genetic variations, activation of specific morbidity-related pathways and epigenetic modifications can all occur in OSA and lead to high degree of heterogeneity in OSA-induced end-organ morbidity.

OSA: obstructive sleep apnoea.

Health And Disease), a large body of literature has provided compelling evidence to the validity of this theoretical construct, and its implications in many of the diseases affecting our society. Indeed, Barker and Osmond ${ }^{17}$ found high rates of death due to coronary heart disease in areas with elevated neonatal mortality in England and Wales and put forth the proposal that intrauterine deprivation was an important mediator of such mortality. Numerous studies have subsequently documented associations between low birth weight and increased incidence of heart disease, hypertension, and type 2 diabetes, as well as relevant markers such as insulin resistance and dyslipidaemias ${ }^{18,19}$. Extrapolation of this early exposure linkage to other diseases such as cancer, neurodegenerative disorders and overall accelerated ageing has gained substantial traction in recent years, further attesting to the importance of internal and external environmental cues to the modulation of homeostatic processes, including those involved in tissue repair and regeneration ${ }^{20-25}$.

\section{DEVELOPMENTAL PLASTICITY AND EPIGENETIC PROCESSES}

Developmental plasticity can be defined as the ability of one genotype to produce a range 
of phenotypes in response to environmental conditions. Such plasticity can occur at the level of individual cells, an organ, or the whole organism. As the embryo develops, lineage restriction events reduce cellular pluripotency such that cellular plasticity declines with developmental age. Epigenetic processes represent a major regulatory mechanism by which the environment modulates gene transcription during development and may explain the decrease of cellular plasticity by the establishment of cell-specific epigenetic profiles during development ${ }^{26}$. Moreover, epigenetic processes are responsible for transgenerational inheritance in several complex traits ${ }^{27-29}$. Epigenetics studies focus on three related molecular mechanisms for genome regulation: deoxyribonucleic acid (DNA) modifications, histone modifications and non-coding ribonucleic acids (ncRNAs) ${ }^{30-41}$. DNA modification is the covalent modification of a nucleotide in the DNA sequence. The most studied DNA modifications are the addition of a methyl or hydroxylmethyl group at the fifth position of the cytosine nucleotide $(\mathrm{C})$, termed as 5-methylcytosine (5mC) and 5-hydroxylmethylcytosine (5hmC), respectively. In the mammalian genome, these additions occur almost exclusively in the context of a cytosine-guanine (CG) dinucleotide and may regulate the expression of the cognate genes. The second epigenetic mechanism in genome regulation is determined by the organization of the histones in the nucleosomes. Histone modifications include methylation, acetylation, phosphorylation, ubiquitination, sumoylation, citrullination, and adenosine diphosphate ribose (ADP)-ribosylation. Either working as individual marks or in a combinatorial pattern, histone modifications are major regulators of gene expression, and can act as activating or repressing marks. The third layer of epigenetic regulation is given by ncRNAs. This category includes several types of RNA molecules which are not coding for proteins, but may have a function on genome regulation, such as micro RNAs (miRNA), small interfering RNAs (siRNA) and long non-coding RNAs (lncRNA). At defined developmental stages, DNA and chromatin are modified leading to variations in gene regulation that will result in the establishment of specific cell lineages (cell differentiation) ${ }^{30-41}$. Environmental factors have an impact on how faithfully patterns of epigenetic modifications are maintained throughout adult life $\mathrm{f}^{42}$. Furthermore, epigenetic programming can be reversed by environmental interventions in early or adult life, such as treatment with epigenetic drugs, nutrition or maternal care ${ }^{42}$. In this regard, it has been recently reported for example that activities such as exercise induce DNA methylation changes in human skeletal muscle and human adipose tissue, potentially affecting the regulation of organismal metabolism ${ }^{43,44}$.

In the context of DOHAD, the "thrifty phenotype" hypothesis proposes that poor nutrition in early life produces permanent changes in glucose-insulin metabolism and results in poor foetal and infant growth and subsequent development of type 2 diabetes and metabolic syndrome ${ }^{45,46}$. In the original report by Barker and Osmond ${ }^{17}, 407$ men born in Hertfordshire (1920-1930), and 266 men and women born in Preston (1935-1943) in the United Kingdom, whose weights and size had been recorded in detail at birth and at one year of age were analysed ${ }^{17}$. The prevalence of the "thrifty phenotype" syndrome correlated inversely with birth weight. This observation indicates that altered gestational conditions leading to "small for gestational age" (SGA) 
children might have induced phenotypic changes, which are then manifested as increased cardiometabolic risk in late adulthood. These earlier observations suggested that early environmental exposures, such as gestational hyperglycaemia, maternal obesity and overfeeding during pregnancy, epigenetically alter the programming of genes resulting in a long-term imprint on gene expression that lasts into adulthood. There is now evidence of a sizeable contribution of early-life influences such as maternal high fat diet or malnutrition on the risk of becoming an obese adolescent or adult and of developing obesity-associated diseases in adulthood. Indeed, the rapidly rising incidence of childhood obesity could reflect the same processes, whereby developmental factors will affect adult disease risk via several pathways, all of which depend on developmental plasticity. These long-term effects are now believed to be mediated by epigenetic changes and evidence supportive of such assumptions is emerging ${ }^{32,47}$.

\section{OBSTRUCTIVE SLEEP APNOEA DURING PREGNANCY AND CONSEQUENCES TO THE OFFSPRING}

Based on the aforementioned considerations, one of the potential windows of vulnerability linking OSA and epigenetic susceptibility determinants of later onset of disease would be the occurrence of OSA during pregnancy. To this effect, we should be aware that two-thirds of women in the United States are currently overweight or obese at the time of conception, and that pre-conception obesity is fraught with higher risk for the gestation itself and for the foetal outcomes ${ }^{48-52}$. Furthermore, paternal obesity is not without risk either ${ }^{53}$. In addition, early in gestation - first and early second trimester - maternal insulin sensitivity can actually increase modestly ${ }^{54}$, leading to elevated maternal adipose tissue lipid storage.

Pregnancy, and particularly late gestation, has been associated with a relatively high prevalence of altered sleep patterns including restricted sleep duration, fragmented sleep, snoring, and especially OSA ${ }^{55-67}$. Experimental evidence in murine models has conclusively demonstrated that OSA can induce changes in insulin sensitivity and promote obesogenic behaviours as well as hypertension, i.e., correlates of pre-eclampsia ${ }^{68-74}$. Similarly, preliminary findings in pregnant women suggest that disrupted sleep, specifically as a result of snoring or OSA is associated with increased risk for insulin resistance and pre-eclampsia ${ }^{75-81}$. Perturbations in sleep duration during pregnancy are also suggested to be accompanied by altered function in the mother ${ }^{82-84}$ and also affect developmental trajectories in the offspring 85 .

Sleep fragmentation (SF) and IH are fundamental characteristics of OSA. Both paradigms can be induced individually or in combination in rodent models to study the effects of $\mathrm{OSA}^{86}$. Offspring of rats exposed to $\mathrm{IH}$ showed lower birth weight and an increased propensity for high body weight later in life when compared with offspring of pregnant rats exposed to normal oxygen levels - room air ${ }^{87}$. Several recent studies indicate that snoring mothers are more likely to have SGA infants and exhibit higher risk for perinatal complications ${ }^{88-92}$. Furthermore, and as a validity preamble to the putative distal yet adverse role of OSA on the overall well-being of the offspring, we have shown that implementation 
of the hallmark characteristics of OSA in experimental mice during late gestation promotes the risk of their offspring developing significant metabolic dysfunction when they reach adulthood. Indeed, exposure of pregnant mice to SF during late gestation is accompanied by increased risk of metabolic dysfunction in offspring manifesting as increased body weight accrual, dyslipidaemia and insulin resistance. In addition, systematic exploration of epigenetic changes in the offspring revealed adiponectin gene (Adipoq) epigenetic alterations in adipocytes from visceral white adipose tissue as well as forkhead box protein $\mathrm{O} 1$ (Foxo1) epigenetic changes in liver in a sex-dimorphic pattern of expression $^{93-95}$. Genome-wide exploration of the offspring revealed 2148 differentially methylated regions (DMR)-associated genes with known functions that are mechanistically relevant to obesity and metabolic syndrome, such as cocaine- and amphetamine-regulated transcript prepopeptide (Cartpt), RAC-beta serine/threonine-protein kinase (Akt2), apolipoprotein E (Apoe), insulin receptor 1 (Insr1), and so on, such that the overrepresented pathways and gene networks were primarily related to metabolic regulation and inflammatory responses ${ }^{96}$. In addition, involvement of the unfolded protein response has been identified, whereby activation of the cellular integrated stress response appears to be critical during gestation to induce the affected phenotype in the offspring, via alterations in circulating exosomal miRNAs ${ }^{97}$. More recently, we also explored the consequences of experimental $\mathrm{IH}$ during late gestation and mimicking OSA desaturation patterns on the offspring ${ }^{98}$. Similar to the aforementioned study, body weight, food intake, adiposity index, fasting insulin, triglycerides and cholesterol levels were all significantly higher in gestationally-exposed male offspring at 24 weeks of age (corresponding to mid adulthood in human) but not in exposed female offspring ${ }^{98,99}$. Late gestational $\mathrm{IH}$ also altered metabolic expenditure and locomotor activities in male offspring, and increased number of pro-inflammatory macrophages in their visceral white adipose tissues. Assessment of methylation changes in the genomic DNA of adipocytes from visceral fat revealed 1520 DMRs associated with 693 genes, corresponding to molecular pathways related to metabolic regulation and inflammation. Thus, both gestational SF and IH induce metabolic dysfunction as reflected by increased body weight and adiposity index in adult male offspring that is paralleled by epigenomic alterations and inflammation in visceral fat, suggesting that perturbations to foetal environment by OSA during pregnancy can have long-term detrimental effects on the foetus, and lead to persistent metabolic dysfunction in adulthood via epigenetic changes (Fig. 2). Prospective studies aimed at identifying unique epigenetic risk signatures in offspring of mothers suffering from OSA would be highly desirable and will likely take place once the initial large scale epidemiological studies on OSA in pregnancy are completed ${ }^{100}$.

In addition to these considerations, we should also contemplate the possibility that unique conditions during gestation facilitating the emergence of premature birth may in turn impose an undue risk of developing OSA later in life. This specific perspective is much less developed in the current published literature, and the only evidence to this effect is that children who were born prematurely 
OSA

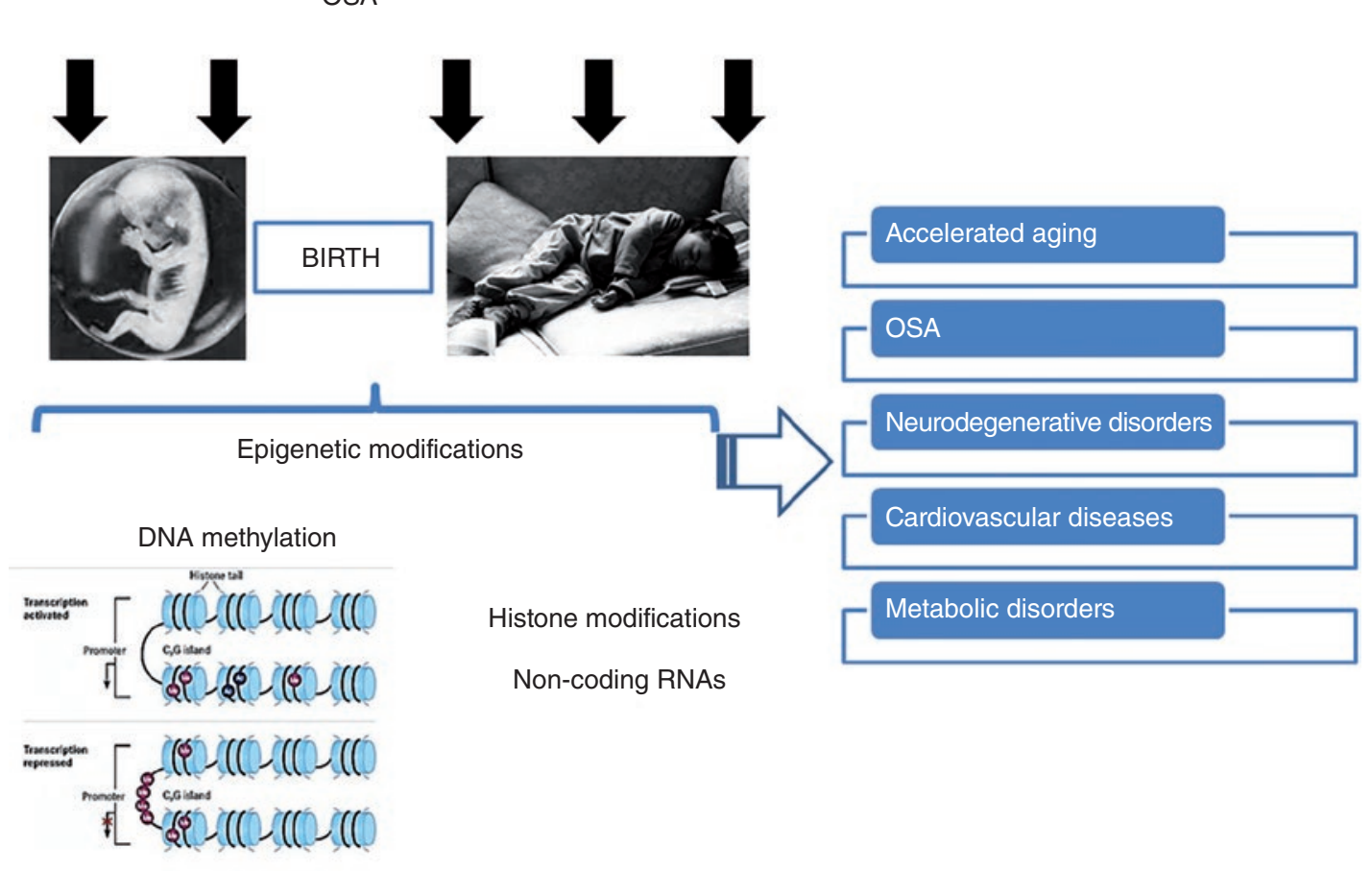

FIGURE 2. Schematic diagram illustrating that the presence of OSA during gestation or early postnatal life can induce epigenetic changes potentially leading to increased risk for a variety of aging-related diseases in adulthood.

DNA: deoxyribonucleic acid; OSA: obstructive sleep apnoea; RNA: ribonucleic acid.

are at a greater risk of suffering from OSA as they grow $^{101}$. To date, it remains unclear whether there is a causal relation between the determinants of pre-term birth and the long-term development of the various contributing mechanisms to the occurrence of upper airway dysfunction. However, one could easily contemplate that perturbations during critical gestational periods that would induce premature delivery may also differentially and epigenetically modify unique gene subsets involved for example in craniofacial skeletal growth or aspects of respiratory control that are relevant to sleep-disordered breathing. These hypothetical scenarios merit future studies, particularly considering that identification of a set of risk biomarkers for future development of OSA may enable precision medicine and risk prevention approaches.

\section{STUDIES ON OBSTRUCTIVE SLEEP APNOEA IN CHILDREN AND EPIGENETIC MODIFICATIONS}

We have thus far explored the potential impact of gestational OSA on offspring. However, the epigenetic window of susceptibility 
is not closed at birth, and rather extends in progressively declining fashion throughout life. Thus, the possibility that the presence of OSA during infancy and childhood may lead to epigenetic changes is not farfetched. The cumulative evidence in this context is more limited however and will be reviewed here.

Initial studies in our laboratory indicated that early exposures to IH, mimicking apnoea of prematurity, were accompanied by evidence of delayed brain and spinal cord myelination that persisted for extensive periods after cessation of the exposures ${ }^{102}$. Similarly, exposures of young rats to IH during a critical developmental period were accompanied by long-term alterations in frontal cortical dopaminergic pathways that were sexually dimorphic as far as the persistence of neurobehavioural deficits ${ }^{103}$. Incidentally, since our initial observations of persistent respiratory changes in the context of IH exposures during early post-natal life ${ }^{87}$, subsequent work identified age-related declines in respiratory plasticity following exposures to IH that may persist into adulthood ${ }^{104-107 .}$

In more recent studies, Nanduri et al. ${ }^{108}$ identified epigenetic changes in the carotid body as one of the potential mechanisms associated with deregulation of respiratory control following exposures to IH. Under the overarching hypothesis raised by our work above that the IH of apnoea of prematurity predisposes to autonomic dysfunction in adulthood, these investigators showed that adult rats that were exposed to IH as neonates exhibited exaggerated responses to hypoxia by the carotid body and adrenal chromaffin cells, which regulate cardio-respiratory function, and that such persistent alterations resulted in irregular breathing with apnoea and hypertension. Nanduri et al. ${ }^{108}$ further demonstrated that the reduced expression of the superoxide dismutase 2 (SOD2) gene, which encodes the antioxidant enzyme superoxide dismutase 2, was associated with increased methylation of a single C-phosphate-G (CpG) dinucleotide in close proximity to the transcription start site of the gene, and that administration of decitabine, an inhibitor of DNA methylation, during neonatal IH exposures prevented the expression of the phenotype in adulthood. Of note, when these exposures were implemented in adult rats, the reversal of the phenotype occurred only after short exposures (10 days) but not prolonged exposures (30 days), and evidence for increased DNA methylation of genes encoding anti-oxidant enzymes was also reported ${ }^{109}$.

It is now well established that premature birth, and possibly the presence of apnoea of prematurity, are accompanied by an increased risk of cardiovascular and metabolic disease during adulthood ${ }^{110-112}$. To further examine the viability of the epigenetic hypothesis, we exposed neonatal mice to $\mathrm{IH}$, and then allowed them to recover in normoxia till they reached adulthood ${ }^{113}$. IH-exposed mice manifested evidence of endothelial dysfunction, as shown by reduced reperfusion indices after tail vessel occlusion indicating abnormal flow mediated vasodilation. Furthermore, the IH-exposed mice also exhibited impaired vasodilatory responses to acetylcholine, and endothelial cells that were harvested from their mesenteric arteries expressed higher levels of angiotensin-converting enzyme (ACE) and reactive oxygen species, along with elevated plasma 
angiotensin-II (AGT) levels. Furthermore, increased DNA methylation patterns of the ACE1 and the AGT genes were apparent in the endothelial cells of the IH-exposed mice ${ }^{113}$.

To the best of my knowledge, only two studies examining evidence for epigenetic modifications have been conducted thus far in children with OSA. In the initial study, Kim et al ${ }^{114}$ showed that forkhead box P3 (FOXP3) gene, which critically regulates the conversion and function of $\mathrm{T}$ regulatory lymphocytes, is more likely to display increased methylation in the promoter region among children with OSA who exhibit increased systemic inflammatory responses, the latter being associated with increased risk for end-organ morbidity. Similarly, the heterogeneously increased risk for cardiovascular morbidity in children with OSA was examined using endothelial post-occlusive hyperaemic responses, which are dependent on the expression and function of endothelial nitric oxide synthase gene (NOS3). Since expression of the NOS3 gene is regulated by epigenetic mechanism, we explored whether children with OSA and abnormal endothelial function showed evidence of increased methylation of NOS3 compared to children with OSA but preserved endothelial function ${ }^{115}$. Among the 36 children with OSA with endothelial dysfunction $(n=11)$ and preserved endothelial function $(n=25)$, as well as 25 controls without OSA, pyrosequencing of the proximal promoter region of the eNOS gene revealed significant differences in methylation among the OSA children with abnormal endothelial function in a CPG site located at position -171 (relative to transcription start site), approximating important transcriptional elements, suggesting that the reduced expression of NOS3 in these children may be due to the increased methylation of the NOS3 gene. It will be important to evaluate the potential relationships between reversibility of these epigenetic changes and their concordance with reversal of end-organ morbidity following treatment of OSA. Furthermore, longitudinal tracking of unique epigenetic signatures from childhood into adulthood among OSA patients may permit identification of atrisk individuals for premature development of cardiometabolic or neurodegenerative diseases.

\section{STUDIES ON OBSTRUCTIVE SLEEP APNOEA IN ADULTS AND EPIGENETIC MODIFICATIONS}

There is only very scarce evidence regarding the occurrence of epigenetic changes in the context of OSA in adults. The initial study followed on our characterization in murine models of the effect of IH simulating OSA on malignant solid tumours ${ }^{116}$. In this context, we wished to identify circulating tumour cell free DNA (ctDNA) in mice with a standardised solid tumour who were exposed to $\mathrm{IH}$ and corresponding controls (CO) and assess whether IH elicited epigenetic changes in tumoural $\mathrm{DNA}^{117}$. Significant associations between plasma ctDNA concentrations and tumour size, weight and invasiveness emerged. More interestingly, using a methylation microarray-based approach, we identified 2094 gene regions showing significant differential ctDNA modifications that reflected unique sets of molecular pathways that are deregulated in cancer progression and transcription start sites in highly variable regions in chromosomes 7, 13, 14 and $X$ that may reflect hotspots for DNA deletions. As such, exposures to IH increase 
the shedding of ctDNA into circulation, which carries epigenetic modifications that may characterise cell populations within the tumour and provide opportunities for precision therapeutic approaches. Indeed, a subset of differentially regulated microRNAs within circulating exosomes in OSA murine models provide corroborating evidence that epigenetic mechanisms may play a substantial role in the connection between OSA and cancer ${ }^{118,119}$.

In a recent study of 44 obese patients with OSA aiming to analyse the influence of resting oxygen consumption on global and gene DNA methylation as well as protein secretion of inflammatory markers in blood cells, Lopez-Pascual et al. ${ }^{120}$ found interleukin 6 (IL-6) gene $\mathrm{CpG}$ islands showing evidence of hypomethylation, concordant with serum IL-6 levels being higher in those OSA patients with lower resting energy expenditure. It is therefore possible that epigenetic modifications in inflammatory genes may contribute to the systemic inflammation that is frequently, albeit not universally present among OSA patients.

Finally, we reported on the effects of positive airway pressure therapy on genome-wide epigenetic methylation patterns in monocytes of patients with obesity hypoventilation syndrome. In this study, we found 1847 regions showing significant differential DNA methylation, and bioinformatics analysis of biochemical pathways and gene networks revealed that the differentially methylated genes underlie components of immune responses, and more particularly those targeted by peroxisome proliferation-activated receptors (PPARs), a cluster of genes that play major roles in cardiometabolic and neurodegenerative diseases ${ }^{121-125}$.

These findings are intimately aligned with the reversibility concept mentioned above. Indeed, in studies involving mice exposed to $\mathrm{IH}$ for extended periods of time, we found substantial differential methylation patterns in macrophages within the aorta wall which extensively involved PPARs, and cessation of $\mathrm{IH}$ exposures did not appear to reverse the methylation changes or reduce the pro-atherogenic activity of the macrophages within the aortic wall ${ }^{15}$.

An ongoing clinical trial aimed to resolve some of these issues will hopefully provide some answers to the reversibility questions regarding the morbidity of OSA ${ }^{126}$. In the interim, a specific miRNA signature has been identified as a reliable predictor of CPAP therapeutic response in patients with OSA and resistant hypertension, opening the doors of personalised approaches in this disease ${ }^{127}$.

\section{EVOLVING CONCEPTS ON MICROBIOME AND OBSTRUCTIVE SLEEP APNOEA-INDUCED MORBIDITY}

The microbiome is a vast, complex and highly regulated microbial community that $\mathrm{co}^{-}$ habitates with every other living organism. It is inordinately susceptible and reactive to a large repertoire of both intrinsic and extrinsic changes in the host, and concurrently plays major roles in many of the host functional systems ${ }^{128-130}$. Recent studies have indicated that altered gut microbiome in the mother during gestation can impose profound changes in the offspring phenotype by altering the 


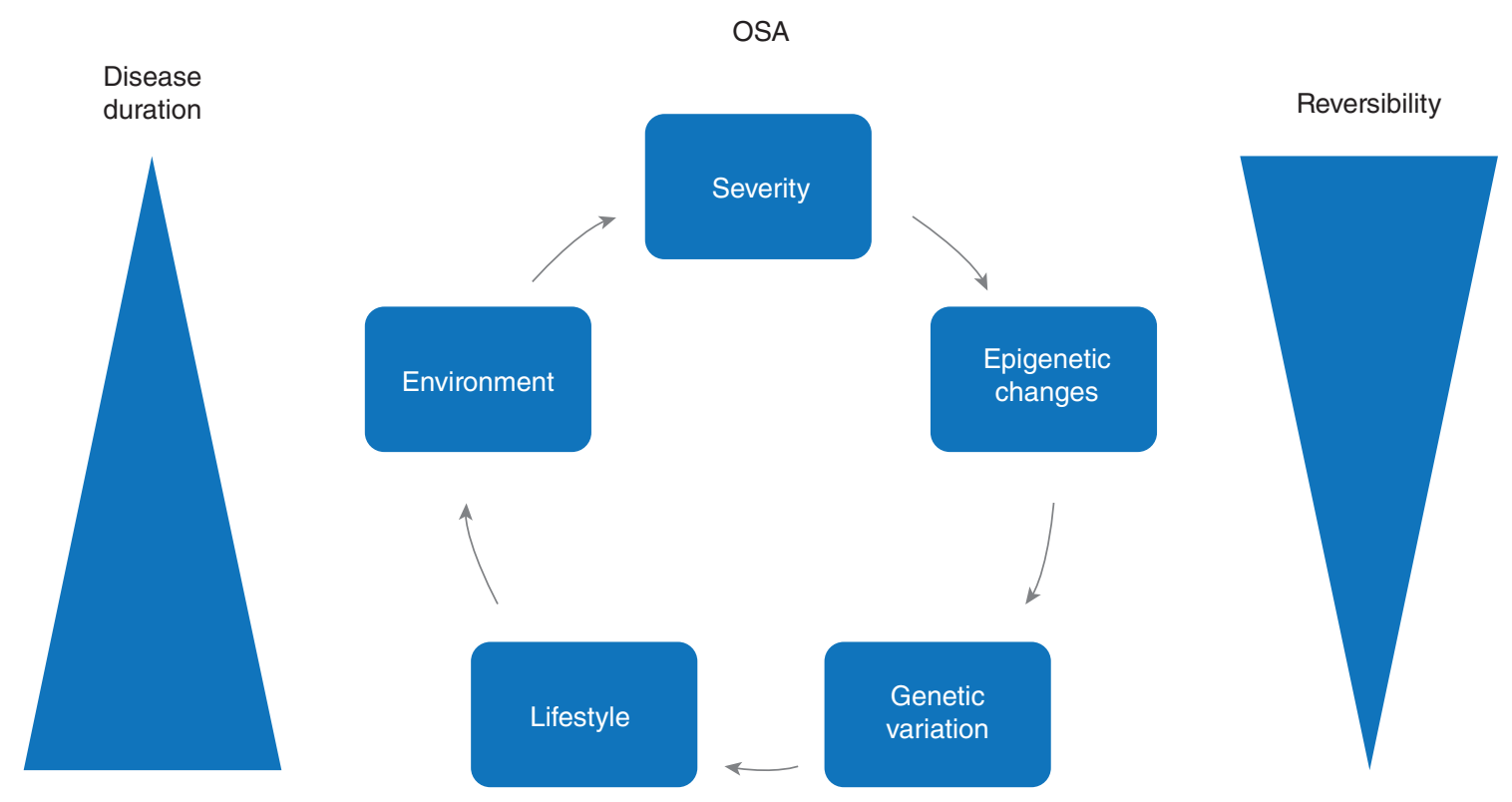

End-organ dysfunction

Figure 3. Schematic diagram depicting the potential interactions between OSA disease severity, lifestyle and environmental conditions, genetic variance, and epigenetic modifications on the reversibility of OSA-induced end-organ morbidity as a function of OSA duration. OSA: obstructive sleep apnoea.

offspring microbiome, and that such changes can occur both via placenta or during the early transitional periods after birth at the time of the constitutional evolution of the microbiome in the offspring ${ }^{131-134}$. Congruent with these observations, experimentally-induced modifications of the maternal microbiome may result in a variety of dysfunctional phenotypes in the offspring ${ }^{135-140}$, and even elicit specific epigenetic changes ${ }^{141}$. Although there is no published evidence as to whether the presence of OSA modified the maternal microbiome, it would be unlikely that such changes would not occur, particularly considering the fact that gut microbiota are extensively altered by the presence of $\mathrm{IH}, \mathrm{SF}$, or sleep patterns in mice ${ }^{142-144}$. Furthermore, OSA-associated changes in gut microbiota have been inferred in children with OSA ${ }^{145}$, appear to be associated with both cardiovascular and metabolic consequences ${ }^{144,146,147}$, and are not readily reversible ${ }^{148}$. Accordingly, it will be important to explore how OSA during pregnancy affects the maternal, placental, and offspring microbiota and their contributions to gestational and offspring outcomes. In addition, the potential modification of long-term risks imposed by OSA may be modifiable by targeted interventions of the microbiome. 


\section{CONCLUSIONS}

Experimental murine models mimicking hallmark components of OSA lead to the emergence of the morbid phenotypes that are characteristically encountered in patient with OSA. These morbidities appear to involve epigenetic processes (Figs. 1-3). Depending on the developmental stage of the occurrence of OSA, the putative role of such epigenetic changes may differ. In early onset OSA (i.e., gestational or postnatal), the epigenetic modifications may not impose immediate morbid consequences but may also promote gene alterations that will become manifest only much later in life, i.e., early antecedents of adult disease. When OSA occurs later in life, i.e., when the epigenetic window is less susceptible, occurrence of selected epigenetic changes in relevant genes and pathways may dictate the potential for reversibility of the morbid consequences of OSA. Hopefully, these concepts of uninterrupted continuum in disease, whereby diseases traditionally associated with older age should in reality be viewed as starting in childhood or even in foetal life will prompt future research efforts in these directions.

In addition, based on the evidence presented here, it is conceivable that with increased duration of disease, OSA will be accompanied by a gradually diminished reversibility of relevant morbid phenotypes. If such assumptions are indeed accurate, we should conceivably redesign our approaches to randomised controlled therapeutic trials in OSA by either taking into account antecedent disease duration (a virtually impossible challenge), or down estimating the effect sizes of therapeutic interventions and the predicted beneficial outcomes of such treatments, while adequately increasing cohort size needs for appropriately powered studies.

\section{ACKNOWLEDGEMENTS}

FINANCIAL SUPPORT: The author is supported by the Herbert T. Abelson Chair and National Institutes of Health grants HL130984 and NS034939.

\section{CONFLICTS OF INTEREST}

The author declares no conflict of interest.

\section{REFERENCES}

1. Marin JM, Carrizo SJ, Vicente E, Agusti AG. Long-term cardiovascular outcomes in men with obstructive sleep apnoea-hypopnoea with or without treatment with continuous positive airway pressure: an observational study. Lancet. 2005;365:1046-53.

2. Pan L, Xie X, Liu D, Ren D, Guo Y. Obstructive sleep apnoea and risks of all-cause mortality: preliminary evidence from prospective cohort studies. Sleep Breath. 2016;20:345-53.

3. Ferini-Strambi L, Lombardi GE, Marelli S, Galbiati A. Neurological deficits in obstructive sleep apnea. Curr Treat Options Neurol. 2017;19:16.

4. Sánchez-de-la-Torre M, Campos-Rodriguez F, Barbé F. Obstructive sleep apnoea and cardiovascular disease. Lancet Respir Med. 2013;1:61-72.

5. Koren D, Dumin M, Gozal D. Role of sleep quality in the metabolic syndrome. Diabetes Metab Syndr Obes. 2016;9:281-310.

6. Campos-Rodriguez F, Martinez-Garcia MA, Martinez M et al. Association between obstructive sleep apnea and cancer incidence in a large multicenter Spanish cohort. Am J Respir Crit Care Med. 2013;187:99-105.

7. Martínez-García MA, Campos-Rodriguez F, Durán-Cantolla J et al. Obstructive sleep apnea is associated with cancer mortality in younger patients Sleep Med. 2014;15:742-8.

8. Almendros I, Gozal D. Intermittent hypoxia and cancer: Undesirable bed partners? Respir Physiol Neurobiol. 2017 Aug 14. pii: S1569-9048(17)301878. doi: 10.1016/j.resp.2017.08.008. In press.

9. Gozal D, Ham SA, Mokhlesi B. Sleep apnea and cancer: Analysis of a nationwide population sample. Sleep. 2016;39:1493-500.

10. Gozal D, Farré R, Nieto FJ. Obstructive sleep apnea and cancer: Epidemiologic links and theoretical biological constructs. Sleep Med Rev. 2016;27: 43-55.

11. Jonas DE, Amick HR, Feltner C et al. Screening for Obstructive Sleep Apnea in Adults: Evidence Report and Systematic Review for the US Preventive Services Task Force. JAMA. 2017;317:415-433. Erratum in: JAMA. 2017; 317:1278.

12. McEvoy RD, Antic NA, Heeley E et al. CPAP for Prevention of Cardiovascular Events in Obstructive Sleep Apnea. N Engl J Med. 2016;375:919-31. 
13. Martinez-García MA, Campos-Rodriguez F, Javaheri S, Gozal D. Pro: CPAP and cardiovascular prevention. Should we change our practice or our study designs? Eur Respir J. In press 2018.

14. Gozal D, Khalyfa A, Qiao Z, Almendros I, Farré R. Temporal trajectories of novel object recognition performance in mice exposed to intermittent hypoxia. Eur Respir J. 2017 Dec 14;50. pii: 1701456. doi: 10.1183/13993003.01456-2017. Print 2017 Dec.

15. Cortese R, Gileles-Hillel A, Khalyfa A et al. Aorta macrophage inflammatory and epigenetic changes in a murine model of obstructive sleep apnea: Potential role of CD36. Sci Rep. 2017;7:43648.

16. Barker DJ. Fetal origins of coronary heart disease. BMJ. 1995;311:171-4.

17. Barker DJ, Osmond C. Infant mortality, childhood nutrition, and ischaemic heart disease in England and Wales. Lancet. 1986;1:1077-81.

18. Waterland RA, Michels KB. Epigenetic epidemiology of the developmental origins hypothesis. Annu Rev Nutr. 2007;27:363-88.

19. Murphy MO, Cohn DM, Loria AS. Developmental origins of cardiovascular disease: impact of early life stress in humans and rodents. Neurosci Biobehav Rev. 2017;74(Pt B):453-65.

20. Bateson P, Barker D, Clutton-Brock T et al. Developmental plasticity and human health. Nature. 2004;430:419-21.

21. Gabbianelli R, Damiani E. Epigenetics and neurodegeneration: role of early-life nutrition. J Nutr Biochem. 2018;57:1-13.

22. Jasiulionis MG. Abnormal Epigenetic Regulation of Immune System during Aging. Front Immunol. 2018;9:197.

23. Ashapkin VV, Kutueva LI, Vanyushin BF. Aging as an Epigenetic Phenomenon. Curr Genomics. 2017;18:385-407.

24. Ravlić S, Škrobot Vidaček N, Naniić L et al. Mechanisms of fetal epigenetics that determine telomere dynamics and health span in adulthood. Mech Ageing Dev. 2017 Aug 26. pii: S0047-637430161-6. doi: 10.1016/j.mad.2017.08.014. [Epub ahead of print]

25. Ren R, Ocampo A, Liu GH, Izpisua Belmonte JC. Regulation of stem cell aging by metabolism and epigenetics. Cell Metab. 2017;26:460-74.

26. Feinberg AP, Irizarry RA. Evolution in health and medicine Sackler colloquium: tochastic epigenetic variation as a driving force of development, evolutionary adaptation, and disease. Proceedings of the National Academy of Sciences of the United States of America. 2010;107 Suppl 1:1757-64.

27. Godfrey KM, Lillycrop KA, Burdge GC, Gluckman PD, Hanson MA. Non-imprinted epigenetics in fetal and postnatal development and growth. Nestle Nutr Inst Workshop Ser. 2013;71:57-63.

28. Soubry A. Epigenetics as a Driver of Developmental Origins of Health and Disease: Did We Forget the Fathers? Bioessays. 2018 Jan;40(1). doi: 10.1002/ bies.201700113. Epub 2017 Nov 23.

29. Cao-Lei L, de Rooij SR, King S, Matthews SG, Metz GAS, Roseboom TJ, Szyf M. Prenatal stress and epigenetics. Neurosci Biobehav Rev. 2017 May 18. pii: S0149-7634(16)30726-6. doi: 10.1016/j.neubiorev.2017.05.016. [Epub ahead of print]

30. Burdge GC, Hoile SP, Uller T et al. Progressive, transgenerational changes in offspring phenotype and epigenotype following nutritional transition. PloS one. 2011;6:e28282.

31. Low FM, Gluckman PD, Hanson MA. Developmental plasticity and epigenetic mechanisms underpinning metabolic and cardiovascular diseases. Epigenomics. 2011;3:279-94.

32. Godfrey KM, Inskip HM, Hanson MA. The long-term effects of prenatal development on growth and metabolism. Semin Reprod Med. 2011;29:25765.

33. El-Osta A, Brasacchio D, Yao D et al. Transient high glucose causes persistent epigenetic changes and altered gene expression during subsequent normoglycemia. J Exp Med. 2008;205:2409-17.

34. Brasacchio D, Okabe J, Tikellis C et al. Hyperglycemia induces a dynamic cooperativity of histone methylase and demethylase enzymes associated with gene-activating epigenetic marks that coexist on the lysine tail. Diabetes. 2009;58:1229-36.

35. Cahan P, Daley GQ. Origins and implications of pluripotent stem cell variability and heterogeneity. Nat Rev Mol Cell Biol. 2013;14:357-68.
36. Wu H, Zhang Y. Mechanisms and functions of Tet protein-mediated 5-methylcytosine oxidation. Genes Dev. 2011;25:2436-52.

37. Ghirlando R, Giles K, Gowher $\mathrm{H}$ et al. Chromatin domains, insulators, and the regulation of gene expression. Biochim Biophys Acta. 2012;1819:644-51.

38. Jenuwein T, Allis CD. Translating the histone code. Science. 2001;293: 1074-80.

39. Mattick JS, Makunin IV. Non-coding RNA. Hum Mol Genet. 2006;15 Suppl 1:R17-29.

40. Ritchie W, Rasko JE, Flamant S. MicroRNA target prediction and validation. Adv Exp Med Biol. 2013;774:39-53.

41. Jaenisch R, Bird A. Epigenetic regulation of gene expression: how the genome integrates intrinsic and environmental signals. Nat Genet. 2003;33 Suppl:245-54.

42. Szyf M, Bick J. DNA methylation: a mechanism for embedding early life experiences in the genome. Child Dev. 2013;84:49-57.

43. Barres R, Yan J, Egan B et al. Acute exercise remodels promoter methylation in human skeletal muscle. Cell Metab. 2012;15:405-11.

44. Ronn T, Volkov P, Davegardh C et al. A six months exercise intervention influences the genome-wide DNA methylation pattern in human adipose tissue. PLoS Genet. 2013;9:e1003572.

45. Sharma AM. The thrifty-genotype hypothesis and its implications for the study of complex genetic disorders in man. J Mol Med (Berl). 1998;76:568-71.

46. Sellayah D, Cagampang FR, Cox RD. On the evolutionary origins of obesity: a new hypothesis. Endocrinology. 2014;155:1573-88.

47. Low FM, Gluckman PD, Hanson MA. Developmental plasticity and epigenetic mechanisms underpinning metabolic and cardiovascular diseases. Epigenomics. 2011;3:279-94.

48. Yogev Y, Catalano PM. Pregnancy and obesity. Obstet Gynecol Clin North Am. 2009;36:285-300,

49. Kalliala I, Markozannes G, Gunter MJ et al. Obesity and gynaecological and obstetric conditions: umbrella review of the literature. BMJ. 2017; 359:j4511.

50. Kominiarek MA, Peaceman AM. Gestational weight gain. Am J Obstet Gynecol. 2017;217:642-51.

51. Chandrasekaran S, Neal-Perry G. Long-term consequences of obesity on female fertility and the health of the offspring. Curr Opin Obstet Gynecol 2017;29:180-7.

52. Parnell AS, Correa A, Reece EA. Pre-pregnancy obesity as a modifier of gestational diabetes and birth defects associations: A systematic review. Matern Child Health J. 2017;21:1105-20.

53. Houfflyn S, Matthys C, Soubry A. Male Obesity: Epigenetic origin and effects in sperm and offspring. Curr Mol Biol Rep. 2017;3:288-96.

54. Lain KY, Catalano PM. Metabolic changes in pregnancy. Clin Obstet Gynecol. 2007;50:938-48

55. Beebe KR, Lee KA. Sleep disturbance in late pregnancy and early labor. Perinat Neonatal Nurs. 2007;21:103-8.

56. Facco FL, Grobman WA, Kramer J, Ho KH, Zee PC. Self-reported short sleep duration and frequent snoring in pregnancy: impact on glucose metabolism. Am J Obstet Gynecol. 2010;203:142.e1-5.

57. Chang JJ, Pien GW, Duntley SP, Macones GA. Sleep deprivation during pregnancy and maternal and fetal outcomes: is there a relationship? Sleep Med Rev. 2010;14:107-14

58. Abeysena C, Jayawardana P. Sleep deprivation, physical activity and low income are risk factors for inadequate weight gain during pregnancy: a cohort study. J Obstet Gynaecol Res. 2010;37:734-40.

59. Ayrim A, Keskin EA, Ozol D, Onaran Y, Yiidirim Z, Kafali H. Influence of self-reported snoring and witnessed sleep apnea on gestational hypertension and fetal outcome in pregnancy. Arch Gynecol Obstet. 2011;283:195-9.

60. Louis JM, Koch MA, Reddy UM et al. Predictors of sleep-disordered breathing in pregnancy. Am J Obstet Gynecol. 2018 Feb 2. pii: S0002-9378(18)30080-2. doi: 10.1016/j.ajog.2018.01.031. [Epub ahead of print]

61. Brown NT, Turner JM, Kumar S. The intrapartum and perinatal risks of Sleep-Disordered Breathing in pregnancy: a systematic review and meta-analysis. Am J Obstet Gynecol. 2018 Feb 15. pii: S0002-9378 30147-9. doi: 10.1016/j.ajog.2018.02.004. [Epub ahead of print] 
62. Chirakalwasan N, Amnakkittikul S, Wanitcharoenkul E et al. Continuous positive airway pressure therapy in gestational diabetes with obstructive sleep apnea: A randomized controlled trial. J Clin Sleep Med. 2018 Feb 13. pii: jc-17-00366. [Epub ahead of print]

63. Wilson DL, Walker SP, Fung AM et al. Sleep-disordered breathing in hypertensive disorders of pregnancy: a BMI-matched study. J Sleep Res. 2018 Jan 25. doi: 10.1111/jsr.12656. [Epub ahead of print]

64. Truong K, Guilleminault C. Sleep disordered breathing in pregnant women: maternal and fetal risk, treatment considerations, and future perspectives. Expert Rev Respir Med. 2018 Mar;12:177-189.

65. Ojile J. Sleep disorders + Pregnancy=Possibility of decreasing preterm births. Sleep Health. 2018 Feb;4:5.

66. Reutrakul S, Anothaisintawee T, Herring SJ, Balserak BI, Marc I, Thakkinstian A. Short sleep duration and hyperglycemia in pregnancy: Aggregate and individual patient data meta-analysis. Sleep Med Rev. 2017 Oct 5. pii: S1087-0792(16)30140-X. doi: 10.1016/j.smrv.2017.09.003. [Epub ahead of print]

67. Pamidi S, Kimoff RJ. Maternal sleep-disordered breathing. Chest. 2017 Oct 21. pii: S0012-3692(17)32906-9. doi: 10.1016/j.chest.2017.10.011. [Epub ahead of print]

68. Wang Y, Carreras A, Lee S, Hakim F, Zhang SX, Nair D, Ye H, Gozal D. Chronic sleep fragmentation promotes obesity in young adult mice. Obesity (Silver Spring). 2014 Mar;22:758-62.

69. Trzepizur W, Cortese R, Gozal D. Murine models of sleep apnea: functional implications of altered macrophage polarity and epigenetic modifications in adipose and vascular tissues. Metabolism. 2017; Nov 16. pii: S00260495(17)30319-0. doi: 10.1016/j.metabol.2017.11.008. [Epub ahead of print]

70. Khalyfa A, Qiao Z, Gileles-Hillel A et al. Activation of the integrated stress response and metabolic dysfunction in a murine model of sleep apnea. Am J Respir Cell Mol Biol. 2017;57:477-86.

71. Gozal D, Gileles-Hillel A, Cortese R et al. Visceral white adipose tissue after chronic intermittent and sustained hypoxia in mice. Am J Respir Cell Mol Biol. 2017;56:477-87.

72. Gileles-Hillel A, Kheirandish-Gozal L, Gozal D. Biological plausibility linking sleep apnoea and metabolic dysfunction. Nat Rev Endocrinol. 2016;12: 290-8.

73. Komiya H, Miyoshi C, Iwasaki K et al. Sleep/Wake behaviors in mice during pregnancy and pregnancy-associated hypertensive mice. Sleep. 2018 Mar 1;41.

74. Chen L, Zadi ZH, Zhang J, Scharf SM, Pae EK. Intermittent hypoxia in utero damages postnatal growth and cardiovascular function in rats. J Appl Physiol (1985). 2017 Dec 14. doi: 10.1152/japplphysiol.01066.2016. [Epub ahead of print]

75. Izci Balserak B, Jackson N, Ratcliffe SA, Pack AI, Pien GW. Sleep-disordered breathing and daytime napping are associated with maternal hyperglycemia. Sleep Breath. 2013;17:1093-102.

76. Reichmann JP. Pregnancy-onset habitual snoring, gestational hypertension, and preeclampsia: prospective cohort study. Am J Obstet Gynecol. 2013; 208:507.

77. Hutchison BL, Stone PR, McCowan LM, Stewart AW, Thompson JM, Mitchell EA. A postal survey of maternal sleep in late pregnancy. BMC Pregnancy Childbirth. 2012;12:144.

78. O'Brien LM, Bullough AS, Owusu JT et al. Pregnancy-onset habitual snoring, gestational hypertension, and preeclampsia: prospective cohort study. Am J Obstet Gynecol. 2012;207:487.e1-9.

79. Frederick IO, Qiu C, Sorensen TK, Enquobahrie DA, Williams MA. The prevalence and correlates of habitual snoring during pregnancy. Sleep Breath. 2013;17:541-7

80. Bublitz MH, Monteiro JF, Caraganis A et al. Obstructive sleep apnea in gestational diabetes: a pilot study of the role of the hypothalamic-pituitary-adrenal axis. J Clin Sleep Med. 2018;14:87-93.

81. Reutrakul S, Zaidi N, Wroblewski K et al. Interactions between pregnancy, obstructive sleep apnea, and gestational diabetes mellitus. J Clin Endocrinol Metab. 2013;98:4195-202.
82. Polo-Kantola P, Aukia L, Karlsson H, Karlsson L, Paavonen EJ. Sleep quality during pregnancy: associations with depressive and anxiety symptoms. Acta Obstet Gynecol Scand. 2017;96:198-206.

83. Cai S, Tan S, Gluckman PD, Godfrey KM et al. Sleep quality and nocturnal sleep duration in pregnancy and risk of gestational diabetes mellitus. Sleep. 2017;40.

84. Qiu C, Enquobahrie D, Frederick IO, Abetew D, Williams MA. Glucose intolerance and gestational diabetes risk in relation to sleep duration and snoring during pregnancy: a pilot study. BMC Womens Health. 2010;10:17.

85. Calegare BF, Fernandes L, Tufik S, D’Almeida V. Biochemical, biometrical and behavioral changes in male offspring of sleep-deprived mice. Psychoneuroendocrinology. 2010;35:775-84.

86. Kaushal N, Ramesh V, Gozal D. Human apolipoprotein E4 targeted replacement in mice reveals increased susceptibility to sleep disruption and intermittent hypoxia. Am J Physiol Regul Integr Comp Physiol. 2012;303:R19-29.

87. Gozal D, Reeves SR, Row BW, Neville JJ, Guo SZ, Lipton AJ. Respiratory effects of gestational intermittent hypoxia in the developing rat. Am J Respir Crit Care Med. 2003;167:1540-7.

88. Izci-Balserak B, Pien GW. Sleep-disordered breathing and pregnancy: potential mechanisms and evidence for maternal and fetal morbidity. Curr Opin Pulm Med. 2010;16:574-82

89. Pamidi S, Marc I, Simoneau G et al. Maternal sleep-disordered breathing and the risk of delivering small for gestational age infants: a prospective cohort study. Thorax. 2016;71:719-25.

90. Howe LD, Signal TL, Paine SJ et al. Self-reported sleep in late pregnancy in relation to birth size and fetal distress: the E Moe, Māmā prospective cohort study. BMJ Open. 2015;5:e008910.

91. Xu T, Feng Y, Peng H, Guo D, Li T. Obstructive sleep apnea and the risk of perinatal outcomes: a meta-analysis of cohort studies. Sci Rep. 2014;4:6982.

92. Chen YH, Kang JH, Lin CC, Wang IT, Keller JJ, Lin HC. Obstructive sleep apnea and the risk of adverse pregnancy outcomes. Am J Obstet Gynecol. 2012;206:136.e1-5.

93. Khalyfa A, Carreras A, Almendros I, Hakim F, Gozal D. Sex dimorphism in late gestational sleep fragmentation and metabolic dysfunction in offspring mice. Sleep. 2015;38:545-57.

94, Khalyfa A, Mutskov V, Carreras A, Khalyfa AA, Hakim F, Gozal D. Sleep fragmentation during late gestation induces metabolic perturbations and epigenetic changes in adiponectin gene expression in male adult offspring mice. Diabetes. 2014;63:3230-41.

95. Mutskov V, Khalyfa A, Wang Y, Carreras A, Nobrega MA, Gozal D. Early-life physical activity reverses metabolic and Foxo1 epigenetic misregulation induced by gestational sleep disturbance. Am J Physiol Regul Integr Comp Physiol. 2015;308:R419-30.

96. Cortese R, Khalyfa A, Bao R, Andrade J, Gozal D. Epigenomic profiling in visceral hite adipose tissue of offspring of mice exposed to late gestational sleep fragmentation. Int J Obes (Lond). 2015;39:1135-42.

97. Trzepizur W, Khalyfa A, Qiao Z, Popko B, Gozal D. Integrated stress response activation by sleep fragmentation during late gestation in mice leads to emergence of adverse metabolic phenotype in offspring. Metabolism. 2017 69:188-98.

98. Khalyfa A, Cortese R, Qiao Z et al. Late gestational intermittent hypoxia induces metabolic and epigenetic changes in male adult offspring mice. Physiol. 2017;595:2551-68.

99. Gabory A, Attig L, Junien C. Sexual dimorphism in environmental epigenetic programming. Mol Cell Endocrinol. 2009;304:8-18.

100. Facco FL, Parker CB, Reddy UM et al. NuMoM2b Sleep-Disordered Breathing study: objectives and methods. Am J Obstet Gynecol. 2015;212:542. e1-127.

101. Walfisch A, Wainstock T, Beharier O, Landau D, Sheiner E. Early term deliveries and the risk of pediatric obstructive sleep apnoea in the offspring. Paediatr Perinat Epidemiol. 2017;31:149-56.

102. Cai J, Tuong CM, Zhang Y et al. Mouse intermittent hypoxia mimicking apnoea of prematurity: effects on myelinogenesis and axonal maturation. J Pathol. 2012;226:495-508. 
103. Kheirandish L, Gozal D, Pequignot JM, Pequignot J, Row BW. Intermittent hypoxia during development induces long-term alterations in spatial working memory, monoamines, and dendritic branching in rat frontal cortex. Pediatr Res. 2005;58:594-9.

104. Reeves SR, Gozal D. Respiratory and metabolic responses to early postnatal chronic intermittent hypoxia and sustained hypoxia in the developing rat. Pediatr Res. 2006;60:680-6.

105. Reeves SR, Mitchell GS, Gozal D. Early postnatal chronic intermittent hypoxia modifies hypoxic respiratory responses and long-term phrenic facilitation in adult rats. Am J Physiol Regul Integr Comp Physiol. 2006;290:R1664-71.

106. Reeves SR, Gozal D. Developmental plasticity of respiratory control following intermittent hypoxia. Respir Physiol Neurobiol. 2005;149:301-11.

107. Reeves SR, Gozal D. Changes in ventilatory adaptations associated with long-term intermittent hypoxia across the age spectrum in the rat. Respir Physiol Neurobiol. 2006;150:135-43.

108. Nanduri J, Makarenko V, Reddy VD et al. Epigenetic regulation of hypoxic sensing disrupts cardiorespiratory homeostasis. Proc Natl Acad Sci U S A. 2012;109:2515-20.

109. Nanduri J, Peng YJ, Wang N et al. Epigenetic regulation of redox state mediates persistent cardiorespiratory abnormalities after long-term intermittent hypoxia. J Physiol. 2017;595:63-77.

110. Paz Levy D, Sheiner E, Wainstock T, Sergienko R, Landau D, Walfisch A. Evidence that children born at early term (37-38 6/7 weeks) are at increased risk for diabetes and obesity-related disorders. Am J Obstet Gynecol. 2017; 217:588.e1-588.e11.

111. Willemsen RH, de Kort SW, van der Kaay DC, Hokken-Koelega AC. Independent effects of prematurity on metabolic and cardiovascular risk factors in short small-for-gestational-age children. J Clin Endocrinol Metab. 2008;93:452-8.

112. Chu A, De Beritto T. The Perinatal Origins of Cardiovascular Disease. Pediatr Ann. 2015;44:e254-9.

113. Chu A, Gozal D, Cortese R, Wang Y. Cardiovascular dysfunction in adult mice following postnatal intermittent hypoxia. Pediatr Res. 2015;77:425-33.

114. Kim J, Bhattacharjee R, Khalyfa A et al. DNA methylation in inflammatory genes among children with obstructive sleep apnea. Am J Respir Crit Care Med. $2012 ; 185: 330-8$.

115. Kheirandish-Gozal L, Khalyfa A, Gozal D, Bhattacharjee R, Wang Y. Endothelial dysfunction in children with obstructive sleep apnea is associated with epigenetic changes in the eNOS gene. Chest. 2013;143:971-7.

116. Almendros I, Wang Y, Becker L et al. Intermittent hypoxia-induced changes in tumor-associated macrophages and tumor malignancy in a mouse model of sleep apnea. Am J Respir Crit Care Med. 2014;189:593-601.

117. Cortese R, Almendros I, Wang Y, Gozal D. Tumor circulating DNA profiling in xenografted mice exposed to intermittent hypoxia. Oncotarget. 2015;6:556-69.

118. Almendros I, Khalyfa A, Trzepizur W et al. Tumor cell malignant properties are enhanced by circulating exosomes in sleep apnea. Chest. 2016;150:1030-41.

119. Khalyfa A, Almendros I, Gileles-Hillel A et al. Circulating exosomes potentiate tumor malignant properties in a mouse model of chronic sleep fragmentation. Oncotarget. 2016;7:54676-90.

120. Lopez-Pascual A, Lasa A, Portillo MP et al. Low oxygen consumption is related to a hypomethylation and an increased secretion of IL-6 in obese subjects with sleep apnea-hypopnea syndrome. Ann Nutr Metab. 2017;71:16-25.

121. Cortese R, Zhang C, Bao R et al. DNA methylation profiling of blood monocytes in patients with obesity hypoventilation syndrome: effect of positive airway pressure treatment. Chest. 2016;150:91-101.

122. Fuentes E, Guzmán-Jofre L, Moore-Carrasco R, Palomo I. Role of PPARs in inflammatory processes associated with metabolic syndrome (Review). Mol Med Rep. 2013;8:1611-6.

123. Ulrich-Lai YM, Ryan KK. PPARD and stress: implications for aging. Exp Gerontol. 2013;48:671-6.

124. Chen YC, Wu JS, Tsai HD et al. Peroxisome proliferator-activated receptor gamma (PPAR- $\gamma$ ) and neurodegenerative disorders. Mol Neurobiol. 2012;46:114-24.

125. Magri CJ, Gatt N, Xuereb RG, Fava S. Peroxisome proliferator-activated receptor- $\gamma$ and the endothelium: implications in cardiovascular disease. Expert Rev Cardiovasc Ther. 2011;9:1279-94
126. Marin JM, Artal J, Martin T et al. Epigenetics modifications and subclinical atherosclerosis in obstructive sleep apnea: The EPIOSA study. BMC Pulm Med. 2014;14:114.

127. Sánchez-de-la-Torre M, Khalyfa A, Sánchez-de-la-Torre A et al. Precision medicine in patients with resistant hypertension and obstructive sleep apnea: blood pressure response to continuous positive airway pressure treatment. J Am Coll Cardiol. 2015;66:1023-32.

128. Turnbaugh PJ, Ley RE, Hamady M, Fraser-Liggett CM, Knight R, Gordon JI. The Human Microbiome Project. Nature 2007; 449:804-10.

129. Mirzaei MK, Maurice CF. Ménage à trois in the human gut: interactions between host, bacteria and phages. Nat Rev Microbiol 2017;15:397-408.

130. Schmidt TSB, Raes J, Bork P. The human gut microbiome: from association to modulation. Cell. 2018;172:1198-1215.

131. Gomez de Agüero M, Ganal-Vonarburg SC, Fuhrer T et al. The maternal microbiota drives early postnatal innate immune development. Science 2016;351:1296-302.

132. Schei K, Avershina E, Øien T et al. Early gut mycobiota and mother-offspring transfer. Microbiome. 2017;5:107.

133. Mulligan CM, Friedman JE. Maternal modifiers of the infant gut microbiota: metabolic consequences. J Endocrinol. 2017;235:R1-R12.

134. Macpherson AJ, de Agüero MG, Ganal-Vonarburg SC. How nutrition and the maternal microbiota shape the neonatal immune system. Nat Rev Immunol. 2017;17:508-17.

135. Buffington SA, Di Prisco GV, Auchtung TA, Ajami NJ, Petrosino JF, Costa-Mattioli M. Microbial Reconstitution Reverses Maternal Diet-Induced Social and Synaptic Deficits in Offspring. Cell. 2016;165:1762-75.

136. Kim S, Kim H, Yim YS et al. Maternal gut bacteria promote neurodevelopmentalb abnormalities in mouse offspring. Nature. 2017;549:528-32.

137. Jašarević E, Howard CD, Misic AM, Beiting DP, Bale TL. Stress during pregnancy alters temporal and spatial dynamics of the maternal and offspring microbiome in a sex-specific manner. Sci Rep. 2017;7:44182.

138. Wankhade UD, Thakali KM, Shankar K. Persistent influence of maternal obesity on offspring health: Mechanisms from animal models and clinical studies. Mol Cell Endocrinol. 2016;435:7-19.

139. Bruce-Keller AJ, Fernandez-Kim SO, Townsend RL et al. Maternal obesetype gut microbiota differentially impact cognition, anxiety and compulsive behavior in male and female offspring in mice. PLoS One. 2017;12:e0175577.

140. Gray LE, O'Hely M, Ranganathan S, Sly PD, Vuillermin P. The maternal diet, gut bacteria, and bacterial metabolites during pregnancy influence offspring asthma. Front Immunol. 2017;8:365.

141. Tomlinson MS, Bommarito PA, Martin EM et al. Microorganisms in the human placenta are associated with altered CPG methylation of immune and inflammation-related genes. PLoS One. 2017;12:e0188664.

142. Moreno-Indias I, Torres M, Montserrat JM et al. Intermittent hypoxia alters gut microbiota diversity in a mouse model of sleep apnoea. Eur Respir J. 2015;45:1055-65.

143. Khalyfa A, Poroyko VA, Qiao Z et al. Exosomes and metabolic function in mice exposed to alternating dark-light cycles mimicking night shift work schedules. Front Physiol. 2017;8:882.

144. Poroyko VA, Carreras A, Khalyfa A et al. Chronic sleep disruption alters gut microbiota, induces systemic and adipose tissue inflammation and insulin resistance in mice. Sci Rep. 2016;6:35405.

145. Kheirandish-Gozal L, Peris E, Wang Y et al. Lipopolysaccharide-binding protein plasma levels in children: effects of obstructive sleep apnea and obesity. J Clin Endocrinol Metab. 2014;99:656-63.

146. Durgan DJ, Ganesh BP, Cope JL et al. Role of the gut microbiome in obstructive sleep apnea-induced hypertension. Hypertension. 2016;67:469-74.

147. Farré N, Farré R, Gozal D. Sleep Apnea Morbidity: A Consequence of Microbial-Immune Cross-Talk? Chest. 2018 Mar 13. pii: S0012-3692(18)30405-7. doi: 10.1016/j.chest.2018.03.001. [Epub ahead of print]

148. Moreno-Indias I, Torres M, Sanchez-Alcoholado L et al. Normoxic recovery mimicking treatment of sleep apnea does not reverse intermittent hypoxia-induced bacterial dysbiosis and low-grade endotoxemia in mice. Sleep. 2016;39:1891-7. 